\title{
Taxonomic reconsideration of Chinese Lespedeza maximowiczii (Fabaceae) based on morphological and genetic features, and recommendation as the independent species L. pseudomaximowiczii
}

\author{
Dong-Pil JIN, Bo XU' and Byoung-Hee CHOI* \\ Department of Biological Sciences, Inha University, Incheon 22212, Korea \\ ${ }^{1}$ The ECORES Lab, Chengdu Institute of Biology, Chinese Academy of Sciences, Chengdu 610041, China \\ (Received 16 August 2018; Revised 15 September 2018; Accepted 20 September 2018)
}

\begin{abstract}
Lespedeza maximowiczii C. K. Schneid. (Fabaceae) is a deciduous shrub which is known to be distributed in the temperate forests of China, Korea and on Tsushima Island of Japan. Due to severe morphological variations within species, numerous examinations have been conducted for Korean L. maximowiczii. However, the morphology of Chinese plants has not been studied as thoroughly, despite doubts about their taxonomy. To clarify this taxonomic issue, we investigated morphological characters and undertook a Bayesian clustering analysis with microsatellite markers. The morphological and genetic traits of Chinese individuals varied considerably from those of typical L. maximowiczii growing in Korea. For example, petals of the former had a different shape and bore long claws, while the calyx lobes were diverged above the middle and the upper surface of the leaflet was pubescent. Their terete buds and spirally arranged bud scales were distinct from those within the series/section Heterolespedeza, which includes L. maximowiczii. Our Bayesian clustering analysis additionally included L. buergeri as an outgroup. Those results indicated that the Chinese samples clustered into a lineage separated from L. maximowiczii (optimum cluster, $K=2$ ), despite the fact that the latter is grouped into the same lineage with L. buergeri. Therefore, we treat those Chinese plants as a new species with the name L. pseudomaximowiczii.
\end{abstract}

Keywords: Bayesian clustering analysis, Lespedeza maximowiczii, Lespedeza pseudomaximowiczii, microsatellite, morphology, new species

Lespedeza maximowiczii C. K. Schneid. is a deciduous shrub in the family Fabaceae (Choi, 2007). This species is traditionally considered to belong to section (Nakai, 1939) or series (Akiyama, 1988) Heterolespedeza Nakai, which is characterized by flattened buds and distichously arranged bud scales (Nakai, 1939; Akiyama, 1988). In a recent revision of the taxonomic system for Lespedeza Michx. (Ohashi and Nemoto, 2014), Heterolespedeza was placed in section Macrolespedeza Maxim., reflecting the results of molecular phylogenetic studies (Han et al., 2010; Xu et al., 2012). Simultaneously, series Formosae S. Akiyama \& H. Ohba (including L. thunbergii (DC.) Nakai, L. davidii Franch., L. homoloba Nakai, and L. patens Nakai) was treated as a synonym of section Macrolespedeza (Ohashi and Nemoto, 2014). First described based on Faurie's collection (Schneider, 1907), L. maximowiczii was sampled from Quen-san (= Wonsan-si), Hamgyeongnam-do, Korea. The origins of its local name were reviewed by Chang et al. (2004). Now, this species is known to be distributed in the temperate forests of Korea, China, and Japan (Akiyama, 1988; Choi, 2007; Ohashi et al., 2009). Plants grow abundantly on the mountains in all Korean provinces (Choi, 2007), and are also found in Anhui, Henan and Zhejiang provinces of central China (Ohashi et al., 2009). In Japan, this species is restricted to the northern part of Isl. Tsushima (Akiyama, 1988), close to the Korean Peninsula. Therefore, the highest concentrations of plants are in China

\footnotetext{
*Author for correspondence: bhchoi@inha.ac.kr
} 
and Korea, two regions separated by ca. $1170 \mathrm{~km}$.

The morphological characters of $L$. maximowiczii vary widely, with many intra taxa being described, such as var. tomentella, var. elongata, and f. alba (Nakai, 1927; Akiyama, 1988). To clarify the circumscription on this species, those characters have been examined several times for Korean and Japanese individuals (Lee, 1965; Hatusima, 1967; Akiyama, 1988), and the taxonomic rank of this species and intra taxa has also been changed by researchers. The Japanese individuals are regarded as typical forms even though some have smaller calyces (ca. 2 mm long) (Hatusima, 1967; Akiyama, 1988). However, only a few morphological investigations have been performed with Chinese L. maximowiczii. Although Ohashi et al. (2009) and Huang et al. (2010) revised Chinese Macrolespedeza, shrub forms of Lespedeza, they did not consider L. maximowiczii when observing those specimens. Flower characters are key to distinguishing among Lespedeza species (Akiyama, 1988) but have not been described in minute detail. If plants of that species have been geographically isolated between China and Korea/Japan for a long time, it is possible that Chinese individuals show distinct morphological traits and should be treated as intra taxa or a new species. In the case of the related L. buergeri Miq., which belongs to the same series/section Heterolespedeza, plants in the Korean population differ from those of Chinese and Japanese populations because of their smaller bracteoles (Jin et al., 2016b). Hence, morphological examination of Chinese individuals is required to confirm its taxonomic entity.

Several phylogenetic studies on Lespedeza have utilized molecular markers such as cpDNA and nrITS (Han et al., 2010; $\mathrm{Xu}$ et al., 2012), and nrITS and nuclear gene PGK (Xu et al, 2017). However, Chinese and Korean L. maximowiczii have never been sequenced in parallel. It is difficult to delimit species of Macrolespedeza because the resolution of markers is low due to frequent hybridization, reticulate evolution, and rapid diversification (Han et al., 2010; Xu et al., 2012, 2017). The PGK markers show relatively high resolution for section Junceae (Maxim.) H. Ohashi \& T. Nemoto but not for Macrolespedeza. Therefore, other markers are needed. We employed microsatellite markers developed from this genus (Jin et al., 2016a). Because they are highly polymorphic and distributed across multiple loci (Duminil et al., 2012), they can be used to reveal genetic diversity among populations (Sunnucks, 2000) as well as to delimit closely related taxa in various groups, such as those within the genera of Carapa Aubl., Phoenix L. and Quercus L. (Pintaud et al., 2010; Duminil et al., 2012; Lee et al., 2014).

Here, our research aims were to (1) compare the morphological and genetic traits of typical L. maximowiczii with those of Chinese samples currently identified as $L$. maximowiczii and (2) clarify the taxonomic entity of plants growing in China.

\section{Materials and Methods}

\section{Morphological examination and survey of geographical distribution}

To compare the morphological characters of typical Lespedeza maximowiczii with those of Chinese plants identified the same way, we collected specimens from both countries and deposited them in the Herbarium of Inha University (IUI). Additional morphological examination was conducted by observing specimen from the following herbaria: the Korea National Arboretum (KH) and the Chinese Academy of Sciences, Beijing (PE). We also gathered more information throughout the Chinese Virtual Herbarium (CVH) (http://www.cvh.ac.cn/); and by looking at photograph and geographical distribution of Chinese specimens held at the Hangzhou Botanical Garden (HHBG); the Institute of Botany, Jiangsu Province and Chinese Academy of Sciences (NAS); and the Kunming Institution of Botany (KUN). All observations of morphological characters were made with a stereomicroscope (Leica MZ8; Wetzlar, Germany), and criteria for floral measurements were mainly those stipulated by Akiyama (1988).

\section{Sampling, DNA extraction, and microsatellite polymerase chain reaction}

Genetic traits were studied using leaves sampled from typical forms (Korean, $n=87)$ and Chinese individuals $(n=38)$ which were identified as L. maximowiczii (Table 1). Plants of $L$. maximowiczii also grow, albeit only in small numbers, on Isl. Tsushima (Akiyama, 1988). Because of that scarcity, we did not include them in this molecular examination. As the outgroup, we analyzed one population each from China and Japan of the related species L. buergeri $(\mathrm{n}=14$ and $\mathrm{n}=11$, respectively).

Genomic DNA ( $3 \mu \mathrm{g})$ was extracted from silica-dried leaves with an MG Plant Genomic DNA Extraction SV Miniprep Kit (MGmed, Seoul, Korea), according to the manufacturer's instructions. For Bayesian cluster analysis, we used the following eight microsatellite loci (Jin et al., 2016a): LMS3, LMS18, LMS28, LMS39, LMS45, LMS47, LMS53, and LMS58. The polymerase chain reaction (PCR) protocol utilized those markers with a GeneAmp PCR System 2700 Thermal Cycler (Applied Biosystems, Foster City, CA, USA). Each reaction mixture (10 $\mu \mathrm{L}$ total volume) contained $5 \mathrm{ng}$ of DNA, 
Table 1. Sampling information for Lespedeza species used in this study.

\begin{tabular}{clcc}
\hline \hline Code & \multicolumn{1}{c}{ Population locality } & Coordinates & $\begin{array}{c}\text { No. of } \\
\text { samples }\end{array}$ \\
\hline Typical Lespedeza maximowiczii in Korea & & \\
JS & Jeoksangsan Mt., Jeoksang, Muju, Jeonbuk, Korea & $35^{\circ} 56^{\prime} \mathrm{N}, 127^{\circ} 41^{\prime} \mathrm{E}$ & 29 \\
GM & Peak Gama, Samdong, Namhae, Gyeongnam, Korea & $34^{\circ} 44^{\prime} \mathrm{N}, 128^{\circ} 01^{\prime} \mathrm{E}$ & 7 \\
NS & Namsan Mt., Tap, Gyeongju, Gyeongbuk, Korea & $35^{\circ} 45^{\prime} \mathrm{N}, 129^{\circ} 13^{\prime} \mathrm{E}$ & 17 \\
DS & Daesosan Mt., Chuksan, Yeongdeok, Gyeongbuk, Korea & $36^{\circ} 31^{\prime} \mathrm{N}, 129^{\circ} 25^{\prime} \mathrm{E}$ & 12 \\
BR & Bongraesan Mt., Bongnae, Goheung, Jeonnam, Korea & $34^{\circ} 26^{\prime} \mathrm{N}, 127^{\circ} 30^{\prime} \mathrm{E}$ & 6 \\
NR & Dongil, Goheung, Jeonnam, Korea & $34^{\circ} 30^{\prime} \mathrm{N}, 127^{\circ} 28^{\prime} \mathrm{E}$ & 16 \\
Chinese plant & Huang Mt., Huangshan, Anhui, China & $30^{\circ} 13^{\prime} \mathrm{N}, 118^{\circ} 13^{\prime} \mathrm{E}$ & 9 \\
H & Jigong Mt., Xinyang, Henan, China & $31^{\circ} 53^{\prime} \mathrm{N}, 114^{\circ} 4^{\prime} \mathrm{E}$ & 14 \\
JG & Tianmu Mt., Linan, Zhejiang, China & $30^{\circ} 19^{\prime} \mathrm{N}, 119^{\circ} 26^{\prime} \mathrm{E}$ & 15 \\
TM & & & $33^{\circ} 52^{\prime} \mathrm{N}, 111^{\circ} 19^{\prime} \mathrm{E}$ \\
L. buergeri & Funiu Mt., Lushi, Henan, China & $35^{\circ} 47^{\prime} \mathrm{N}, 138^{\circ} 30^{\prime} \mathrm{E}$ & 14 \\
FN & Kayaga Mt., Hokuto, Yamanashi, Japan & & 11 \\
\hline
\end{tabular}

plus $5 \mu \mathrm{L}$ of $2 \times$ Plus Mix (Dongsheng Biotech, Guangdong, China) that comprised $0.4 \mathrm{mM}$ dNTPs, $2 \times$ PCR buffer with $4 \mathrm{mM} \mathrm{MgSO}_{4}$, and $0.4 \mathrm{U} / \mu \mathrm{L}$ of Taq DNA polymerase. The mixtures also contained the appropriate $0.08 \mu \mathrm{M}$ forward M13 (-21)-tagged primer, a $0.3 \mu \mathrm{M}$ reverse primer, and a $0.3 \mu \mathrm{M}$ M13 (-21) labeled fluorescent marker (NED, PET, VIC, 6FAM). Conditions included initial denaturation at $94^{\circ} \mathrm{C}$ for 3 min; then 30 cycles at $94^{\circ} \mathrm{C}$ for $30 \mathrm{~s}, 53^{\circ} \mathrm{C}$ for $30 \mathrm{~s}$, and $72^{\circ} \mathrm{C}$ for $45 \mathrm{~s}$; without a final extension. Afterward, the PCR products were visualized on $2 \%$ agarose gels and resolved to genotype on an ABI 3730XL sequencer with GeneScan 500 LIZ size standards (Applied Biosystems). The sizes of the alleles were determined with GENEMAPPER 3.7 (Applied Biosystems).

\section{Microsatellite data analyses}

Based on genotype data, we analyzed the genetic characters in terms of the number of alleles $\left(N_{\mathrm{a}}\right)$, number of private alleles $\left(N_{\mathrm{p}}\right)$, and expected heterozygosity $\left(H_{\mathrm{e}}\right)$ with GenAlEx 6.5.3 (Peakall and Smouse, 2012). Because the Bayesian clustering method assigns ancestral lineages for all individuals, we were able to use it to compare the genetic structures of Korean and Chinese samples. This analysis was performed with STRUCTURE 2.3.4 (Pritchard et al., 2000), selecting the admixture ancestry and correlated allele frequency models. Ten runs were conducted for each cluster ( $K=1$ to 16 ), with 200,000 burn-ins followed by 200,000 Markov chain Monte Carlo repetitions. To determine the optimum $K$ values, we calculated $\Delta K$ using STRUCTURE HARVESTER (Earl and von Holdt, 2012).

\section{Results and Discussion}

\section{Morphological examination of Chinese plants identified as Lespedeza maximowiczii}

To confirm the taxonomic entity of Chinese plants currently identified as Lespedeza maximowiczii, we compared their morphological traits with those of Korean L. maximowiczii (Fig. 1, Table 2). Our main examination focused on the external morphology of buds, flowers, and leaflets. To avoid any misidentification of individuals collected for this study, we tried to observe the specimen (collection no. K.M. Liu 4846) that had been used originally to report the occurrence of $L$. maximowiczii in China (Kung, 1936). However, despite those attempts, we could not observe any such specimen from the $\mathrm{CVH}$. Therefore, we looked at specimens from the same date and site collected by the same person (collection no. K.M. Liu 4864 ) in the PE herbarium. This enabled us to determine the morphological traits of Chinese plants while preventing any erroneous identifications.

The differences between Chinese plants and typical $L$. maximowiczii are summarized in Table 2. Although flower lengths were similar, i.e., 9.1-(9.8)-10.5 mm for Chinese individuals versus $8.2-(9.5)-10.9 \mathrm{~mm}$ for the Korean samples, the ratio of petal claw to lamina length varied. In particular, the standard petals of Chinese plants showed relatively longer claws $(2.4-[2.7]-3.0 \mathrm{~mm})$ than those of the typical specimen $(0.7-[1.1]-1.5 \mathrm{~mm})$. The standards were narrower for Chinese samples $(4.1-[4.8]-5.5 \mathrm{~mm}$ vs. $4.4-$ 


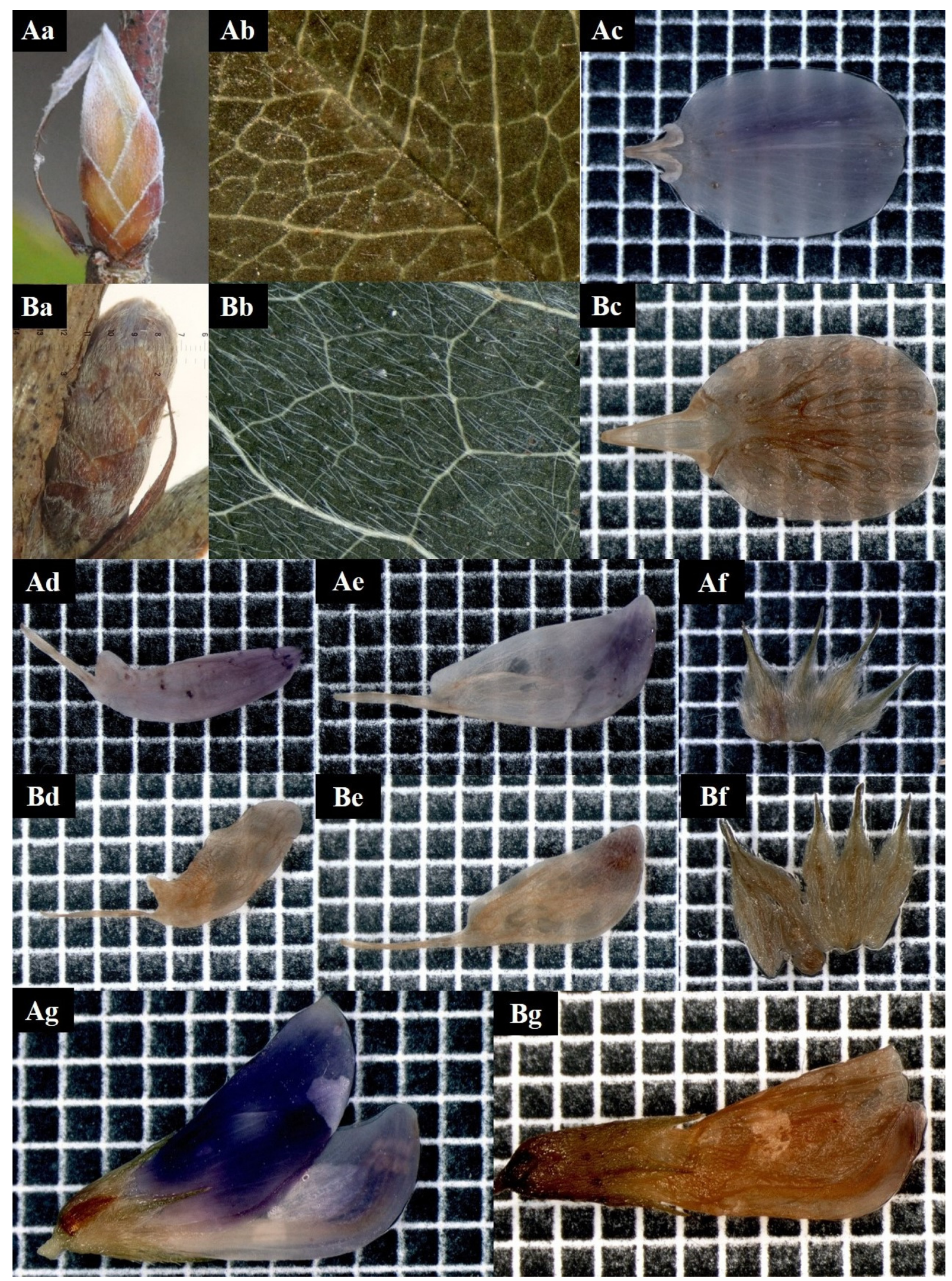

Fig. 1. Comparison of morphological traits between typical Lespedeza maximowiczii and Chinese plant, named L. pseudomaximowiczii. A. Korean L. maximowiczii. B. L. pseudomaximowiczii. a, bud; b, hairs on leaflet; c, standard petal; d, wing petal; e, keel petal; f, calyx; g, flower. 
Table 2. Comparison of morphological traits between typical Lespedeza maximowiczii and Chinese plant identified as L. maximowiczii.

\begin{tabular}{lcc}
\hline \hline & Typical L. maximowiczii & Chinese plant \\
\hline Shape of bud & Flattened & Terete \\
Arrangement of bud scales & Mostly distichous & Spiral \\
Length of flower (mm) & $8.2-(9.5)-10.9$ & $9.1-(9.8)-10.5$ \\
Length of standard petal (mm) & $7.0-(8.5)-10.0$ & $8.7-(9.3)-10.5$ \\
Length of standard petal claw (mm) & $0.7-(1.1)-1.5$ & $2.4-(2.7)-3.0$ \\
Width of standard petal claw (mm) & $4.4-(5.6)-6.8$ & $4.1-(4.8)-5.5$ \\
Length of wing petal claw (mm) & $1.7-(2.4)-2.9$ & $3.1-(3.5)-4.0$ \\
Length of wing petal lamina (mm) & $4.5-(5.4)-6.7$ & $4.3-(4.6)-5.1$ \\
Length of keel petal claw (mm) & $2.0-(2.6)-3.3$ & $3.3-(3.8)-4.4$ \\
Length of keel petal lamina (mm) & $5.6-(6.3)-7.0$ & $4.3-(5.4)-6.2$ \\
Length of calyx tube (mm) & $1.2-(1.5)-2.1$ & $2.2-(2.4)-2.8$ \\
Length of calyx lobe (mm) & $1.5-(2.3)-3.5$ & $1.9-(2.0)-2.2$ \\
Density of hairs on upper surface of leaflet (number per 4 $\left.\mathrm{mm}^{2}\right)$ & $1-(8)-59$ & $86-(144)-218$ \\
\hline
\end{tabular}

Number in parenthesis indicates mean value.

[5.62]-6.8 mm) and they also varied in shape. Whereas those of the Chinese plants were oblong or elliptic, the typical form was elliptic to broad elliptic. For Korean samples, the ratio of claw to lamina length in the wing and keel petals (wing, 1:1.6-[2.3]-2.8; keel, 1:1.7-[2.5]-3.3) closely coincided with previous observations (ratio of ca. 1:2.5 in both petal types) (Akiyama, 1988). This contrasted with length ratios for the Chinese wing (1:1.2-[1.3]-1.6) and keel (1:1.0-[1.4]-1.6). The calyx from Chinese individuals was lobed above the middle portion (tube, 2.2-[2.4]-2.8 mm long; lobe, 1.9-[2.0]$2.2 \mathrm{~mm}$ long), whereas the calyx of the typical form was usually lobed below the middle portion (tube, 1.2-[1.5]-2.1 mm long; lobe, 1.5-[2.3]-3.5 mm long). The density of hairs on the upper surface of a leaflet (defined as the number of hairs per $4 \mathrm{~mm}^{2}$ ) was much higher for the more pubescent Chinese plants (ca. 144) than for the typical L. maximowiczii (ca. 8). Previous examinations have demonstrated that even the leaflets of Korean L. maximowiczii f. tomentella are pubescent up until the fruiting season (Nakai, 1927, Akiyama, 1988). We observed their density of hairs on the upper surface of a leaflet, and it is lower than that of Chinese plants (ca. 51). We also could not regard the Chinese individuals as part of Heterolespedeza because they had terete buds and spirally ordered bud scales (a in Fig. 1B). Therefore, these traits of buds and flowers, considered an important key for identifying Lespedeza species (Akiyama, 1988; Ohashi et al., 2009), were sufficient to suggest that the Chinese individuals are a distinct species.

\section{Genetic characters and Bayesian-clustering based on eight microsatellite loci}

We genotyped 150 individuals of typical L. maximowiczii $(\mathrm{n}=87)$, Chinese plants $(\mathrm{n}=38)$, and L. buergeri $(\mathrm{n}=25)$ based on our microsatellite loci. Most of the eight loci were highly variable for all taxa (Table 3). In particular, LMS18 $\left(H_{\mathrm{e}}\right.$ $=0.753-0.825)$ and $\operatorname{LMS} 39\left(H_{\mathrm{e}}=0.642-0.879\right)$ showed high genetic diversity while LMS53 $\left(H_{\mathrm{e}}=0.000-0.301\right)$ harbored low diversity. The degree of diversity also differed according to taxa, with LMS28 showing a high value in the Chinese samples $\left(H_{\mathrm{e}}=0.694\right)$ but producing low values in the typical L. maximowiczii $\left(H_{\mathrm{e}}=0.203\right)$ and L. buergeri $\left(H_{\mathrm{e}}=0.000\right)$. For LMS45, the Chinese plants presented a lower value $\left(H_{\mathrm{e}}=\right.$ $0.193)$ than that calculated for the Korean L. maximowiczii $\left(H_{\mathrm{e}}\right.$ $=0.595)$ and $L$. buergeri $\left(H_{\mathrm{e}}=0.619\right)$. Our analysis of genetic structure among species (Fig. 2) indicated an optimum cluster of two because $\Delta K$ was highest at $K=2$. Bayesian clustering results $(K=2)$ showed that typical $L$. maximowiczii was grouped in the same cluster with L. buergeri while the Chinese individuals were assigned to an independent lineage (Fig. 3). This might have resulted because of geographic isolation rather than delimitation among species. However, it was not unexpected because Chinese plants were distinct from typical L. maximowiczii, which were, in turn, closer to L. buergeri than to the Chinese plants. At $K=3$ that showed second highest $\Delta K$ value, $L$. maximowiczii and $L$. buergeri were distinguished as separate species rather than being populations within the same species. In both $K=2$ and 3 , most of individuals of 
Table 3. Genetic characteristics of Lespedeza maximowiczii (China vs. typical) and L. buergeri based on 8 microsatellite loci.

\begin{tabular}{|c|c|c|c|c|c|c|c|c|c|c|c|c|}
\hline \multirow[b]{2}{*}{ Locus } & \multicolumn{4}{|c|}{ Chinese plant $(n=38)$} & \multicolumn{4}{|c|}{ Typical L. maximowiczii $(\mathrm{n}=87)$} & \multicolumn{4}{|c|}{ L. buergeri $(\mathrm{n}=25)$} \\
\hline & $N_{\mathrm{a}}$ & $N_{\mathrm{p}}$ & $H_{\mathrm{e}}$ & Range & $N_{\mathrm{a}}$ & $N_{\mathrm{p}}$ & $H_{\mathrm{e}}$ & Range & $N_{\mathrm{a}}$ & $N_{\mathrm{p}}$ & $H_{\mathrm{e}}$ & Range \\
\hline LMS3 & 8 & 2 & 0.708 & $184-220$ & 9 & 3 & 0.651 & $184-212$ & 4 & 1 & 0.490 & $186-210$ \\
\hline LMS18 & 11 & 4 & 0.753 & $216-243$ & 18 & 8 & 0.825 & $208-250$ & 5 & 0 & 0.745 & $208-220$ \\
\hline LMS28 & 5 & 3 & 0.694 & $291-299$ & 3 & 1 & 0.202 & $289-293$ & 1 & 0 & 0.000 & 291 \\
\hline LMS39 & 10 & 4 & 0.827 & $303-321$ & 24 & 14 & 0.879 & $307-341$ & 7 & 0 & 0.642 & $313-333$ \\
\hline LMS45 & 4 & 0 & 0.193 & $295-307$ & 11 & 7 & 0.595 & $295-328$ & 4 & 0 & 0.619 & $298-307$ \\
\hline LMS47 & 6 & 1 & 0.688 & $310-328$ & 7 & 1 & 0.589 & $307-325$ & 7 & 1 & 0.629 & $301-325$ \\
\hline LMS53 & 2 & 0 & 0.301 & $175-178$ & 2 & 0 & 0.011 & $175-178$ & 1 & 0 & 0.000 & 175 \\
\hline LMS58 & 5 & 2 & 0.698 & $239-254$ & 4 & 1 & 0.131 & $236-251$ & 2 & 0 & 0.449 & $245-248$ \\
\hline
\end{tabular}

$N_{\mathrm{a}}$, number of alleles; $N_{\mathrm{p}}$, number of private alleles; $H_{\mathrm{e}}$, expected heterozygosity.

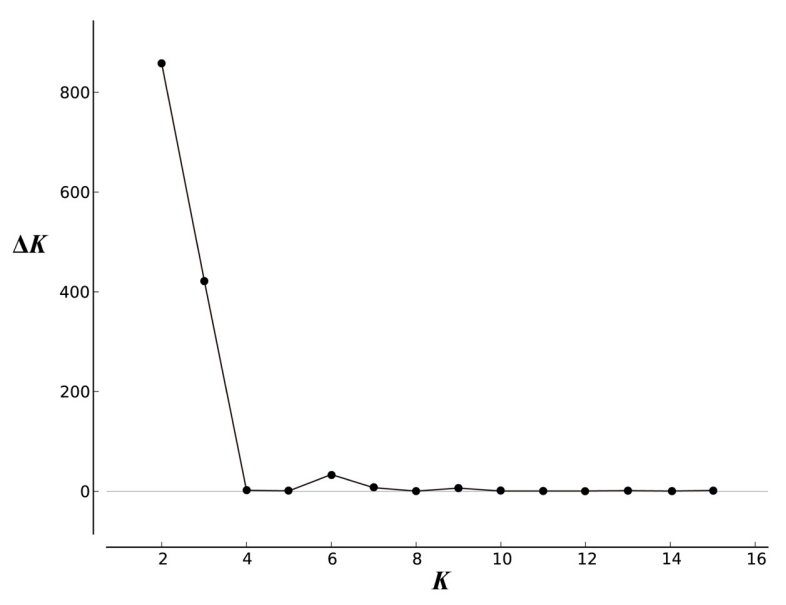

Fig. 2. $\Delta K$ statistics versus number of clusters $(K)$, as calculated based on Bayesian clustering analysis using STRUCTURE.

typical L. maximowiczii, Chinese plant, and L. buergeri are well assigned to one major cluster, but some individuals exhibited a mixed lineage (posterior probabilities that originates from major cluster $[q]<0.9$ ). This mixture is perhaps due to a genetic exchange among Lespedeza species, as has been suggested previously (Xu et al., 2012, 2017). In fact, this assumption is supported by reports of many hybrids in Lespedeza, based on morphological examinations (e.g., Lee, 1965; Akiyama and Ohba, 1982, 1983; Akiyama, 2004). Although those individuals might have resulted from hybridization or introgression, genetic variations within the population could also be a factor. Because of those vagaries, we did not determine their origin(s) in our current exploration.

\section{Taxonomic entity for Chinese plant}

Chinese plant was originally identified as Lespedeza maximowiczii due to morphological similarities. However, our results demonstrated that those individuals should be classified as a distinct species. To confirm this, we compared their morphological traits with other species that grow in China. Because of their terete buds and spiral arrangement of bud scales (Nakai, 1939; Ohashi et al, 2009), it can be difficult

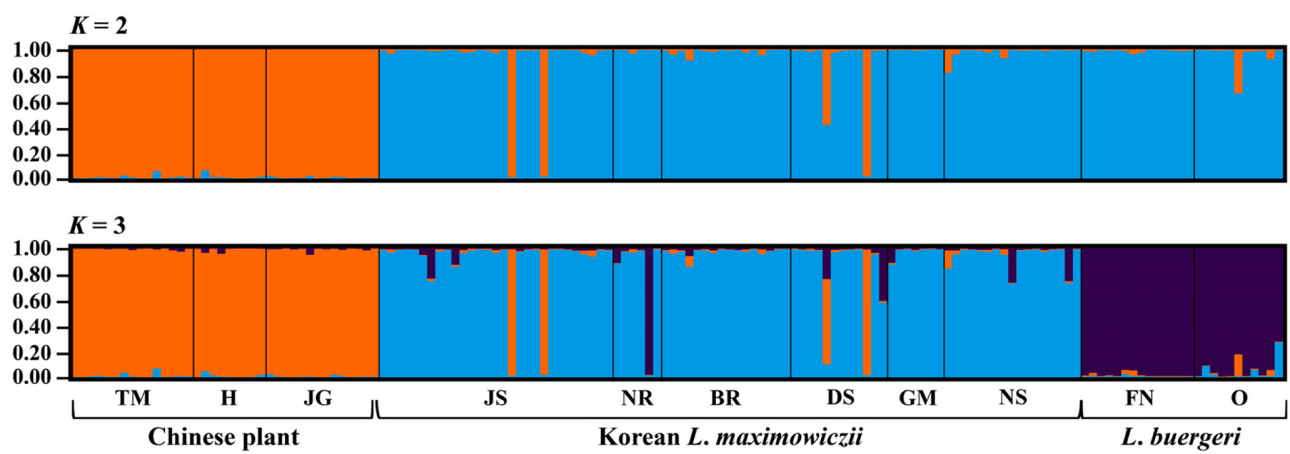

Fig. 3. Results of Bayesian-clustering for between typical Lespedeza maximowiczii and Chinese plant, named L. pseudomaximowiczii, using STRUCTURE, based on 8 microsatellite loci. L. buergeri is included as outgroup. Population codes along x-axis are defined in Table 1. Numbers along $\mathrm{y}$-axis indicate posterior probability of belonging to cluster. 
initially to believe that Chinese plant has ever been classified into section/series Heterolespedeza, members of which generally bear flattened buds and distichously arranged bud scales (incl. L. buergeri and L. dunnii). Among those that feature terete buds and spirally arranged bud scales, $L$. thunbergii (DC.) Nakai subsp. formosa (Vogel) H. Ohashi and L. bicolor Trucz. seem to be closely related to the Chinese plant. The former resembles Chinese plant because it has dense hairs on the leaflet surfaces as well as similarly shaped calyx lobes and leaflets. In fact, several specimens currently annotated as L. maximowiczii in the PE herbarium were originally identified as L. formosa (Vogel) Koehne, and have only recently been treated as synonyms of $L$. thunbergii subsp. formosa (Ohashi et al., 2009). However, L. thunbergii and its intra taxa usually produce longer flowers (ca. $14 \mathrm{~mm}$ long) than those of the Chinese plant, and the standard claw of $L$. thunbergii subsp. formosa (ca. $2.2 \mathrm{~mm}$ long) is shorter than those of the Chinese plant (ca. $2.7 \mathrm{~mm}$ long). The ratios of claw to lamina length in the wing (ca. 1:2.2) and keel petals (ca. 1:2.6) of L. thunbergii subsp. formosa are also different with those of Chinese plant (wing, ca. 1:1.3; keel ca. 1:1.4). L. bicolor is also similar to Chinese plant because of the ratio of claw and lamina lengths in the wing (ca. 1:1.5) and keel (ca. 1:1.5), and the fact that calyx lobed near middle part resembles with Chinese plant. However, L. bicolor bears standard petal attenuated base (Akiyama, 1988), whereas Chinese plant harbors standard petal with clawed base (c in Fig. 1B). In difference with Chinese plant, leaflets of L. bicolor usually are rounded to obtuse at apex, and glabrous. Although their apex of calyx lobes is acute, that of Chinese plant is acuminate. Consequently, Chinese plant is morphologically distinct from L. thunbergii subsp. formosa and L. bicolor.

\section{Taxonomic treatment}

Lespedeza pseudomaximowiczii D. P. Jin, B. Xu \& B. H. Choi, sp. nov. (Figs. 1Ba-g, 4-6).-TYPE: CHINA. Zhejiang, Linan, Tianmu Mt., 18 Aug 2013, Bo Xu 2013-429 (Holotype:

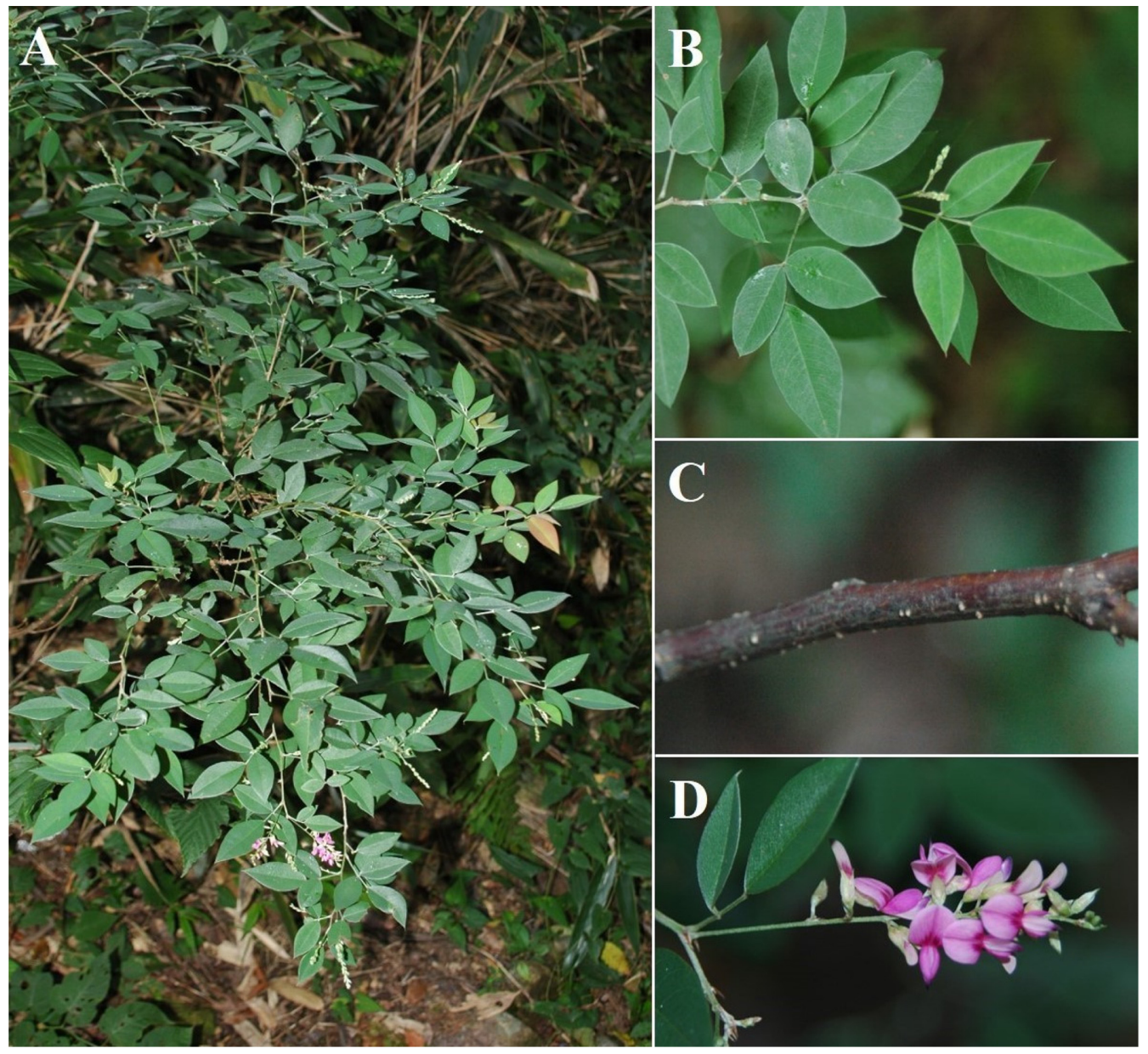

Fig. 4. Chinese plant, named Lespedeza pseudomaximowiczii. A. Habit. B. Branch and leaves. C. Bark. D. Inflorescence. 


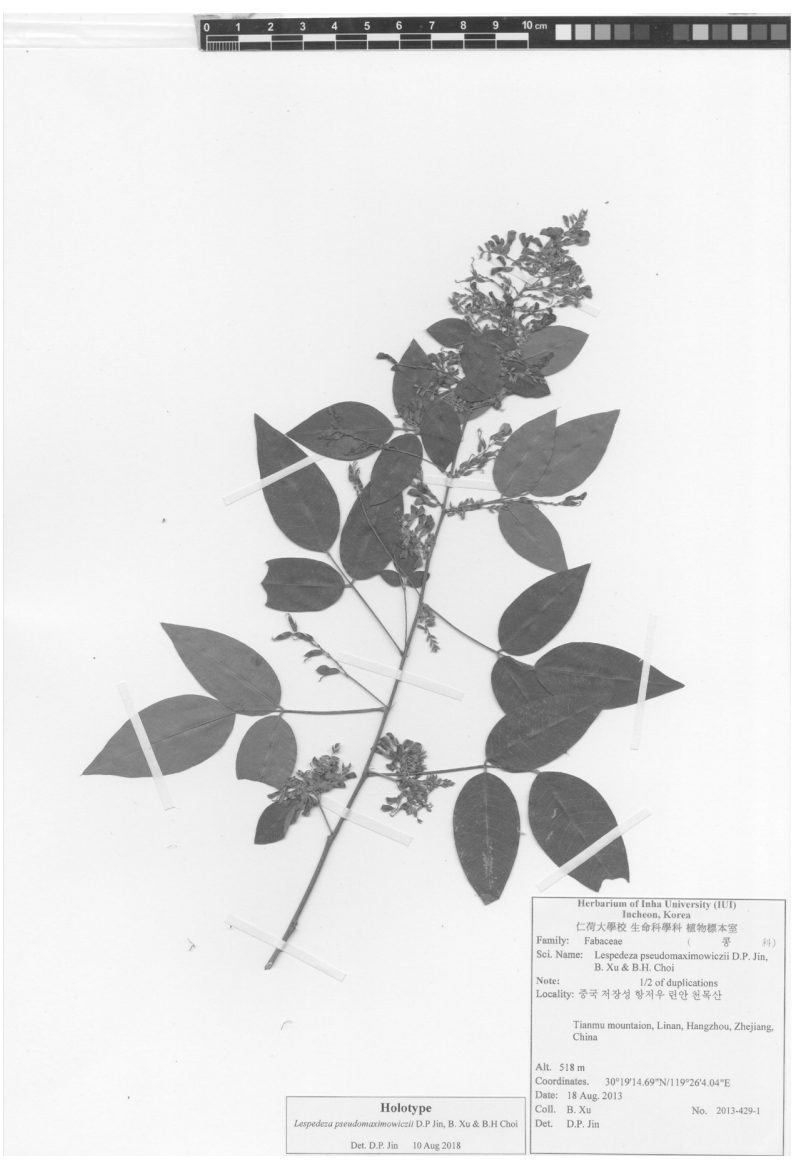

Fig. 5. Holotype of Lespedeza pseudomaximowiczii D. P. Jin, B. Xu \& B. H. Choi.

\section{IUI; Isotype, CDBI).}

Chinese name: Kuan-ye-hu-zhi-zi (宽叶胡枝子).

Shrub erect, 1-3 m tall, much branched at upper part. Branch terete, with sparsely adpressed hairs, light brown to brown, sometimes with black-colored dots; young branches greenishbrown. Leaves trifoliate, petiolate, stipulate, pubescent; rachides $19.7-49.5 \mathrm{~mm}$ long; stipules, linear triangular to linear, brown to dark brown, 3.2-6.4 mm long; terminal leaflets gray-green, elliptic ovate to ovate, 39.1-68.1 mm long, 16.4$35.6 \mathrm{~mm}$ wide, acute to acuminate at apex, rounded or obtuse at base, upper surface pubescent, lower surface pubescent; petioles with adpressed hairs, 14.1-21.6 mm long; petiolules 1-2 mm long, swollen, adpressed or patent hairs. Inflorescence axillary, pseudo-raceme, usually one (rarely two or three) per one leaf, adpressed hair, 25.8-78.8 mm long, 14 to 36 flowered. Flowers 9.1-10.5 mm long, purple to pinkish-purple. Bracteoles at base of calyx, ovate to oblong-ovate, pubescent, ca. $1.2 \mathrm{~mm}$ long. Calyx $4.1-4.7 \mathrm{~mm}$ long, campanulate,
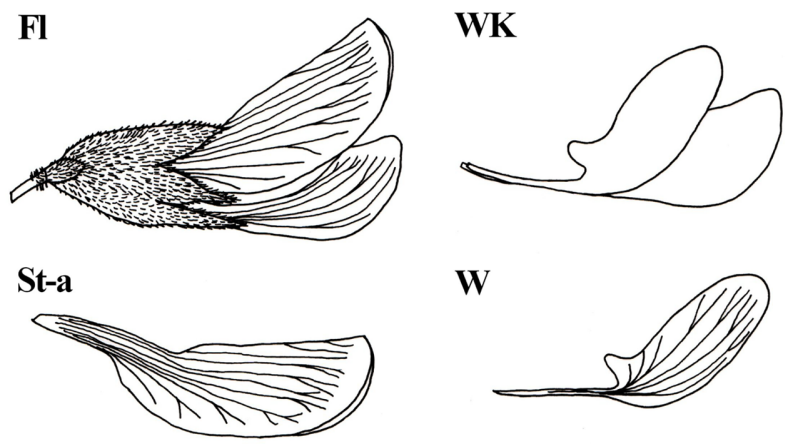

$\mathbf{W}$
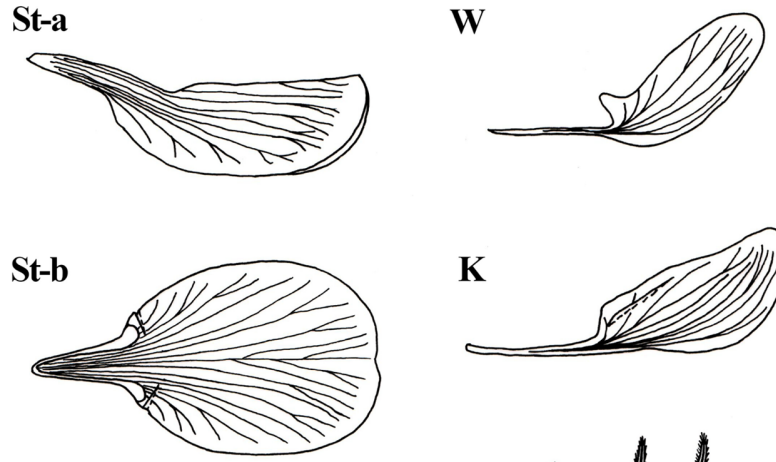

A

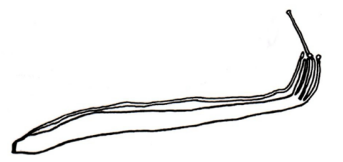

C
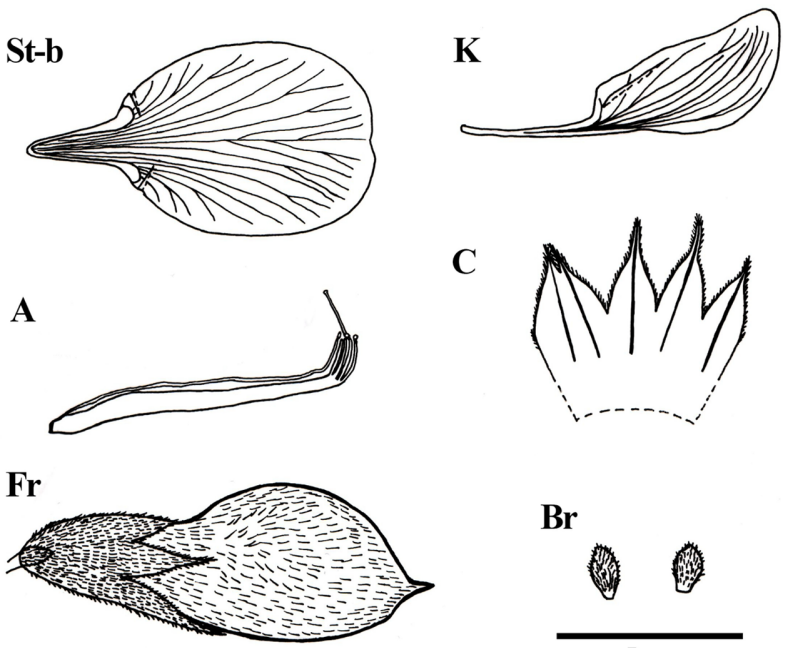

$\mathrm{Br}$

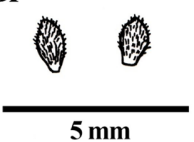

Fig. 6. Illustration for flower and fruit of Lespedeza pseudomaximowiczii. A, androecium; $\mathrm{Br}$, bracteoles; C, calyx; Fl, flower; Fr, fruit; K, keel petal; St-a, lateral view of standard petal; St-b, opened standard petal; W, wing petal; WK, ratio of wing and keel length.

pubescent, middle to above middle four-lobed; lobes subequal in length, acuminate at apex; lateral ones ovate; upper one broad ovate, two-cleft above middle. Standard 8.7-10.5 mm long, 4.1-5.5 mm wide, with auricles; lamina oblong to broad obovate, slightly emarginate at apex, purple inside, paler outside; claw 2.4-3.0 mm long. Wing petal 7.4-8.9 mm long, 1.7-2.2 mm wide; lamina oblong, 4.3-6.2 mm long; claw 3.1$4.0 \mathrm{~mm}$ long, with auricle. Keel petal $8.5-10.4 \mathrm{~mm}$ long, 1.9$2.5 \mathrm{~mm}$ wide; lamina slightly falcate, $4.3-6.2 \mathrm{~mm}$ long; claw 3.3-4.4 mm long. Legume broadly elliptic, ca. $10 \mathrm{~mm}$ long, ca. $5 \mathrm{~mm}$ wide, pilose, spine-tip.

Distribution: Anhui, Henan, Zhejiang (endemic species in China). Flowering: (June-) July-August (-September).

Etymology: The specific epithet is derived from $L$. maximowiczii because of its rough resemblance.

Diagnosis: Lespedeza pseudomaximowiczii resembles $L$. maximowiczii in outward appearance, but differs in the petals 
with long claw and buds (terete, and spirally arranged scales), and in the pubescence on the upper surface of the leaflets. Lespedeza thunbergii subsp. formosa, is also similar to the $L$. pseudomaximowiczii, based on the shape and pubescence of the leaflets and shape of calyx lobes, but differs in flower size (ca. $14 \mathrm{~mm}$ long) and ratios of claw to lamina length in the petals (wing, ca. 1:2.2; keel, ca. 1:2.6). Even though wing and keel petals of $L$. bicolor shows similar ratios of claw and lamina lengths (wing, ca. 1:1.5; keel, ca. 1:1.5), its leaflets (glabrous on upper surface, and usually obtuse at apex) and standard petal with attenuated base are distinct from those of $L$. pseudomaximowiczii.

Additional specimens examined: CHINA. Anhui: Chizhou, Qingyang, Jiuhua Mt., 9 Aug 1934, C. S. Fan \& Y. Y. Li 168 (NAS); Huangshan, 4 Oct 1933, M. Chen 1251 (PE); Huangshan, 28 Aug 1935, T. N. Liou \& P. C. Tsoong 3105 (PE); Huangshan, 4 Oct 1955, M. J. Wang 3668 (PE); Huangshan, 12 Aug 1973, Huangshan team 404 (PE); Huangshan, Yunkusze to Shihszelin, 12 Aug 1935, T. N. Liou \& P. C. Tsoong 2619 (PE); Huangshan, Yixian, Hongtanxiang, 9 Aug 2006, W. Liu et al. A130134 (KUN); Huangshan, Huang Mt., 30 Jul 2013, B. Xu 2013-99 (IUI). Henan: Luanchuan, 23 Sep 2012, J.M. Li 2012-0923 (PE); Luoyang, Luanchuan, Laojun Mt., 3 Aug 1935, K. M. Lion 4864 (PE); Luoyang, Luanchuan, Laojun Mt., 18 Jul 2005, W. Liu et al. $H 40023$ (PE); Luoyang, Luanchuan, Shifangyuan, 23 Aug 1960, Henan team 2059 (PE); Luoyang, Songxian, Huangbaicun, 8 Sep 1956, Henan Forestry Department 735 (PE); Luoyang, Songxian, Longchiman, 15 Aug 1959, Anonymous 34736 (PE); Luoyang, Songxian, Yujiagou, 22 Aug 1960, K. J. Guan \& T. L. Dai 1842 (PE); Nanyang, Tongbai, 16 Aug 1956, Henan Forestry Department 438 (PE); Nanyang, Xixia, Longtangou, 26 Jul 1960, Henan team 1299 (PE); Xinyang, Jigong Mt., 11 Aug 1956, X. Q. Zhang 20150 (PE); Xinyang, Jigong Mt., 12 Aug 2013, B. Xu 2013-265 (IUI). Jiangsu: Zhenjiang, Jurong, Baohua Mt., 18 Jun 1964, S. L. Chen 44 (PE); Wuxi, Yixing, Longchishan Scenic Area, Z. Fang et al. 4 (PE). Jiangxi: Jiujiang, Xiushui, Maozhu Mt., 11 Oct 1989, S. F. Liu 89029 (NAS). Zhejiang: Hangzhou, Chunan, 27 Aug 1978, L. Hong s.n. (HHBG); Hangzhou, Linan, 22 Aug 1957, X. Y. He 26355 (PE); Hangzhou, Linan, 21 Sep 1958, T. N. Liou 30412 (PE); Hangzhou, Linan, 10 Oct 1958, Anonymous 30627 (PE); Hangzhou, Linan, West Tianmu Mt., 27 Jul 1930, T. N. Liou 270 (PE); Hangzhou, Linan, West Tianmu Mt., 25 Jul 1975, K. J. Guan 75446 (PE); Hangzhou, Linan, West Tianmu Mt., 29 Aug 1959, Anonymous 29298 (PE); Hangzhou, Linan, Shunxiwu, 15 Sep 1958, K. J. Guan 30329 (PE); Hangzhou, Linan, Yunxiwu Bridge, 8 Sep 1957, Anonymous 26552 (PE).

\section{Acknowledgments}

The authors are grateful to Prof. X.Y. Zhu and curators of the $\mathrm{KH}$ and $\mathrm{PE}$ herbaria for permitting examinations of specimens. We also thank colleagues J.S. Park and J.W. Park for commenting on this manuscript and editing the figures. This work was supported by the National Research Foundation of Korea (NRF) (No. NRF- 2018R1D1A1B07043030).

\section{Conflict of Interest}

Authors declare that there are no conflicts of interest.

\section{Literature Cited}

Akiyama, S. 1988. A revision of the genus Lespedeza section Macrolespedeza (Leguminosae). The University Museum, The University of Tokyo, Bulletin 33: 1-170.

Akiyama, S. 2004. A new hybrid Lespedeza $\times$ miquelii (Leguminosae). Journal of Japanese Botany 79: 230-234.

Akiyama, S and H. Ohba. 1982. Studies on hybrids in the genus Lespedeza sect. Macrolespedeza (1): a putative hybrid between L. buergeri Miq. and L. cyrtobotrya Miq. Journal of Japanese Botany 57: 232-240.

Akiyama, S and H. Ohba. 1983. Studies on hybrids in the genus Lespedeza sect. Macrolespedeza (2): a hybrid swarm between L. homoloba Nakai and L. kiusiana Nakai. Journal of Japanese Botany 58: 97-104.

Chang, C. S., B. H. Choi, H. Kim and J. Y. Lee. 2004. Reexamination on foreign collectors' sites and exploration routes in Korea: with respect to U. Faurie. Korean Journal of Plant Taxonomy 34: 87-96. (in Korean)

Choi, B. H. 2007. Lespedeza Michx. In The Genera of Vascular Plants of Korea. Park, C.-W. (ed.), Academy Publishing Co., Seoul. Pp. 614-618.

Duminil, J., D. Kenfack, V. Viscosi, L. Grumiau and O. J. Hardy. 2012. Testing species delimitation in sympatric species complexes: the case of an African tropical tree, Carapa spp. (Meliaceae). Molecular Phylogenetics and Evolution 62: 275-285.

Earl, D. A. and B. M. von Holdt. 2012. STRUCTURE HARVESTER: a website and program for visualizing STRUCTURE output and implementing the Evanno method. Conservation Genetics Resources 4: 359-361.

Han, J. E., K. H. Chung, T. Nemoto and B. H. Choi. 2010. Phylogenetic analysis of eastern Asian and eastern North American disjunct Lespedeza (Fabaceae) inferred from nuclear ribosomal ITS and plastid region sequences. Botanical Journal of the Linnean Society 164: 221-235. 
Hatusima, S. 1967. Lespedeza: sects. Macrolespedeza and Heterolespedeza from Japan, Corea and Formosa. Memoirs of the Faculty of Agriculture, Kagoshima University 6: 1-17.

Huang, P. H., H. Ohashi and T. Nemoto. 2010. Lespedeza Michaux. In Flora of China. Vol. 10. Wu, Z. Y., P. H. Raven and D. Y. Hong (eds.), Science Press, Beijing and Missouri Botanical Garden Press, St. Louis, MO. Pp. 302-311.

Jin, D. P., W. B. Cho, I. S. Choi and B. H. Choi. 2016a. Isolation and characterization of 28 microsatellite loci for a Korean endemic, Lespedeza maritima (Fabaceae). Applications in Plant Sciences 4: 1500089.

Jin, D. P., J. H. Lee, B. Xu and B. H. Choi. 2016b. Phylogeography of East Asian Lespedeza buergeri (Fabaceae) based on chloroplast and nuclear ribosomal DNA sequence variations. Journal of Plant Research 129: 793-805.

Kung, H. W. 1936. Lespedeza of North China. Chinese Journal of Botany 1: 19-34.

Lee, J. H., D. P. Jin and B. H. Choi. 2014. Genetic differentiation and introgression among Korean evergreen Quercus (Fagaceae) are revealed by microsatellite markers. Annales Botanici Fennici 51: 39-48.

Lee, T. B. 1965. The Lespedeza of Korea (1). Bulletin of the Seoul National University Forests 2: 1-43.

Nakai, T. 1927. Lespedeza of Japan and Korea. The Forestal Experiment Station of Government General of Chosen 6: 1101.

Nakai, T. 1939. Notulae ad plantas Asiae orientalis (IX). Journal of Japanese Botany 15: 523-541.

Ohashi, H. and T. Nemoto. 2014. A new system of Lespedeza (Leguminosae tribe Desmodieae). Journal of Japanese Botany 89: $1-11$.

Ohashi, H., T. Nemoto and K. Ohashi. 2009. A revision of Les- pedeza subgenus Macrolespedeza (Leguminosae) in China. Journal of Japanese Botany 84: 197-223.

Peakall, R. and P. E. Smouse. 2012. GenAlEx 6.5: genetic analysis in Excel. Population genetic software for teaching and research: an update. Bioinformatics 28: 2537-2539.

Pintaud, J. C., S. Zehdi, T. Couvreur, S. Barrow, S. Henderson, F. Aberlenc-Bertossi, J. Tregear and N. Billotte. 2010. Species delimitation in the genus Phoenix (Arecaceae) based on SSR markers, with emphasis on the identity of the date palm (Phoenix dactylifera). In Diversity, Phylogeny, and Evolution in the Monocotyledons. Seberg, O., G. Petersen, A. Barfod and J. Davis (eds.), Aarhus University Press, Aarhus. Pp. 267-286.

Pritchard, J. K., M. Stephens and P. Donnelly. 2000. Inference of population structure using multilocus genotype data. Genetics 155: 945-959.

Schneider, C. K. 1907. Illustriertes Handbuch der Laubholzkunde: Charakteristik der in Mitteleuropa heimischen und im freien angepflanzten angiospermen Gehölz-Arten und Formen mit Ausschluß der Bambuseen und Kakteen. Vol. 2. Gustav Fischer, Jena, 113 pp. (in German)

Sunnucks, P. 2000. Efficient genetic markers populations biology. Trends in Ecology and Evolution 15: 199-203.

Xu, B., N. Wu, X. F. Gao and L. B. Zhang. 2012. Analysis of DNA sequences of six chloroplast and nuclear genes suggests incongruence, introgression, and incomplete lineage sorting in the evolution of Lespedeza (Fabaceae). Molecular Phylogenetics and Evolution 62: 346-358.

Xu, B., X. M. Zeng, X. F. Gao, D. P. Jin and L. B. Zhang. 2017. ITS non-concerted evolution and rampant hybridization in the legume genus Lespedeza (Fabaceae). Scientific Reports 7: 40057. 